\title{
Another Month
}

\author{
Stephen Hancocks OBE \\ Editor-in-Chief
}

The BDJ Upfront section includes editorials, letters, news, book reviews and interviews. Please direct your correspondence to the News Editor,

Adrian O'Dowd at BDJNews@nature.com. Press releases or articles may be edited, and should include a colour photograph if possible.

$\mathrm{M}$ ay sees the launch of the 2019 National Smile Month (13 May -13 June) an event that has been a fixture in the calendar for over 40 years. ${ }^{1}$ Originally National Smile Week, and originally the British Dental Health Foundation, the extension to a month and the change of name and emphasis to the Oral Health Foundation recognised the shifting times and emphasis for this important subject.

National Smile Month is the largest and longest-running campaign to promote good oral health. Together, with thousands of individuals and organisations, it highlights three key messages, all of which go a long way in helping develop and maintain healthy mouths. They are:

- Brush your teeth last thing at night and on at least one other occasion with a fluoride toothpaste

- Cut down on how much sugary food and drink you have, and how often you have them

- Visit your dentist regularly, as often as they recommend.

Ultimately, the aim is to enable the achievement of good physical and mental wellbeing by improving our oral health. The importance of good oral health is a bedrock of our professional lives and I have observed previously how over the years the mode of delivery has changed from oral health instruction, to education and to promotion. This is a shift from 'do as I say' through 'let me help educate you as to what might be best' to 'let's look at this situation together and work collaboratively'. The latter finds understandable favour in these more liberal times whichever end of the dental mirror, or intra-oral camera, one finds oneself.

Above all the key determinant is motivation. If a patient is motivated to change habits to maintain and improve their oral health then our job is rendered easier and more satisfying; if not then it often seems like a frustrating uphill struggle. Motivation can come from a wide variety of sources but there is no doubt that social pressure is an important driving factor. This is given energy by information derived from multiple sources including the traditional media, social media, the internet, advertising, prevailing fashions, celebrities and so forth. Each of these has an important role to play. An example from my own experience was that I had not heard the term 'plaque' in relation to oral health until I went to dental school in the 1970s. Soon after that it was everywhere in adverts for oral hygiene products and is now so commonplace a term that it seems absurd that there was ever a time when it wasn't in everyday use - let alone having not been identified as the cause of periodontal disease.

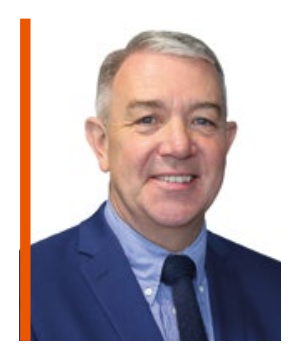

\section{'The aim is to enable the achievement of good physical and mental wellbeing by improving our oral health'}

patients who have the ability to influence popular knowledge and opinion, and taking additional time to develop good relations can pay dividends in terms of positive, accurate coverage for oral health.

The BDA has developed good lines of communication with the media over recent years. Our press and parliamentary colleagues are continually finding spokesmen and women for comment on a whole variety of topics from the political, health service provision, effectiveness of tooth whitening to more bizarre requests such as on vampires and archaeological remains. The important aspect is that journalists know where to come and we can ensure that the information we provide is sound and relevant.
So, events such as Smile Month help to provide a central, albeit once a year, nidus for activity to refresh and reinforce oral health messages. Importantly too, it points a way to reaching those who have the power to influence year-round, namely writers, journalists and broadcasters. Very often myths and misconceptions are given credence through such routes, not necessarily deliberately or indeed maliciously but due to lack of understanding or not having a recognised point of reference to clarify, check or rectify them. Anything we can do to help improve the situation is for the good and this can be achieved at the personal and practice level just as well as at the grand, national level by building good relations with media contacts. We all treat at least some such
Support for National Smile Month also comes from the dental industry whose partnership in oral health promotion is a crucial aspect of success. Without the products that they manufacture and distribute our patients would simply not be able to undertake effective oral hygiene. With the wealth of international readers we now have through the $B D J$ this year's Smile Month could well be the starting point for National campaigns in other countries. I urge you to support the Month and help extend its beneficial reach.

\section{References}

1. Oral Health Foundation. National Smile Month. Available at https://www.dentalhealth.org/what-is-national-smilemonth (accessed April 2019).

DOI: 10.1038/s41415-019-0264-0 